\title{
Machine Learning With AIBO Robots in the Four-Legged League of RoboCup
}

\author{
Stephan K. Chalup, Member, IEEE, Craig L. Murch, and Michael J. Quinlan
}

\begin{abstract}
Robot learning is a growing area of research at the intersection of robotics and machine learning. The main contributions of this paper include a review of how machine learning has been used on Sony AIBO robots and at RoboCup, with a focus on the four-legged league during the years 1998-2004. The review shows that the application-oriented use of machine learning in the four-legged league was still conservative and restricted to a few well-known and easy-to-use methods such as standard decision trees, evolutionary hill climbing, and support vector machines. Method-oriented spin-off studies emerged more frequently and increasingly addressed new and advanced machine learning techniques. Further, the paper presents some details about the growing impact of machine learning in the software system developed by the authors' robot soccer team-the NUbots.
\end{abstract}

Index Terms-Learning systems, legged locomotion, machine learning, RoboCup, robot soccer, robot vision systems, Sony AIBO.

\section{INTRODUCTION}

$\mathbf{T}$ HE ROBOT competition and symposium, RoboCup, is a premier annual event in adaptive multiagent systems. In 1997, it was held for the first time: "RoboCup is an attempt to promote $\mathrm{AI}$ and robotics research by providing a common task for evaluation of various theories, algorithms, and agent architectures" [61]. Research toward RoboCup's ultimate aim "to build a team of robot soccer players, which can beat a human World Cup champion team" [58]_- "is expected to generate multiple spin-off technologies [60]." Another long-term vision of many robotics researchers is to have a team of sophisticated, autonomous, adaptive robots that can explore natural environments and efficiently perform tasks such as search and rescue. This is reflected by the fact that RoboCup has two leagues that address search and rescue, one in simulation and one for realworld robots. However, the majority of the leagues of RoboCup (simulation, f-2000 middle size, f-180 small size, humanoid, four-legged) are soccer leagues (see www.robocup.org).

In the soccer simulation league, matches can be run rapidly to generate a large amount of data necessary for many machine learning algorithms. Therefore, machine learning is frequently used and the simulation league has significantly contributed to the development of reinforcement learning in multiagent domains [4], [98], [109].

Manuscript received July 8, 2005; revised November 24, 2005. This paper was recommended by Associate Editor G. Papadimitriou.

S. K. Chalup and M. J. Quinlan are with the School of Electrical Engineering and Computer Science, University of Newcastle, Callaghan, NSW 2308, Australia (e-mail: chalup@cs.newcastle.edu.au; michael.quinlan@newcastle. edu.au).

C. L. Murch was with the School of Electrical Engineering and Computer Science, University of Newcastle, Callaghan, NSW 2308, Australia. He is now with the Computer Science Corporation (CSC), Macquarie Park, NSW 2113, Australia (e-mail: craig.murch@newcastle.edu.au).

Digital Object Identifier 10.1109/TSMCC.2006.886964
Among the real robot soccer leagues, the middle size and the small size [15] leagues are more easily accessible to machine learning approaches than is the four-legged league with its fully autonomous Sony AIBO ${ }^{1}$ robots and their limited memory and processing power. For example, in the middle size league, each robot can carry a laptop computer, and therefore, has enough power to process sophisticated machine learning techniques. This has led to the development of interesting new methods and spin-off projects [121].

The four-legged league differs in several respects from the other (soccer) leagues of RoboCup. In contrast to the simulation league and the small size league, it is set in a real-world laboratory environment with fully autonomous soccer agents. All teams in the four-legged league must use the same hardware, which is the AIBO robot of Sony Corporation [1], [33], [34], [36]. The four-legged league emphasizes the comparison and development of intelligent software systems rather than the hardware development, although not all teams may use the latest AIBO model. Due to the limited processing power, robot control and team play had to overcome significant challenges during the first years of the four-legged league. However, at the latest competitions, the top teams demonstrated exciting game play. The AIBO's smart dog-like design exhibits characteristic artificial creature features that trigger human observers to emotionally connect with the robots. Recent public performances of "dog teams" attracted cheering crowds of excited robot soccer fans. Currently, the robot soccer teams at RoboCup are probably among the most advanced implementations of machine intelligence on robots known to the public.

Machine learning research has developed models, algorithms, and techniques that have shown excellent results and significant improvements in many application areas such as data mining, pattern recognition, signal processing, and robot control (see, for example, the book by Mitchell [76] or various relevant application papers at the Neural Information Processing Systems (NIPS) conferences [84]).

Machine learning methods not only have the potential to be useful but also, in our opinion, are necessary to solve some of the more challenging robotics tasks and, in particular, for the above-cited long-term goals and visions of RoboCup. It is, therefore, relevant to investigate whether RoboCup teams have successfully applied machine learning methods and gained some advantage from incorporating them into their systems. It would also be interesting to know whether machine leaning research has gained some advancements through RoboCup as

\footnotetext{
${ }^{1} \mathrm{AIBO}$ is a trademark of Sony Corporation.
} 
predicted by the inventors of RoboCup [61], or whether the competitive character of RoboCup eventually inhibits machine learning research in projects associated with the competition [100], [107].

Publications associated with RoboCup have appeared in the RoboCup Symposium proceedings, since 1997, in individual team reports, and in many different journals and conference proceedings related to robotics or machine learning. In the present paper, we extend our pilot study from 2004 [18] and approach the above questions by focusing on the four-legged league since it started in 1998.

There is a similar body of literature covering machine learning in the other leagues of RoboCup. Previous surveys on multiagent systems included links to the history of RoboCup and emphasized the involvement of machine learning [4], [110], [111].

The present paper is intended for the researchers in interdisciplinary fields that combine machine learning and robotics and areas associated with RoboCup [3] or the Federation International Robosoccer Association (FIRA) [2]. Due to the growing impact of these initiatives, the paper could also be helpful for researchers with a more general interest in current developments in artificial intelligence or cybernetics.

The structure of this paper is as follows. First, in Section II, some general issues of the relationship between robotics and machine learning are discussed. In Section III, the soccer environment and robot platforms are described. Then, in Section IV, main machine learning tasks that occur in the four-legged league are explained. The NUbots' approaches are addressed in Section V. The remainder of the paper presents a survey describing how machine learning has been used in the four-legged league (Section VI) and on AIBO robots in general (Section VII). Finally, in Section VIII, possible answers to some of the above questions are discussed.

\section{ROBOT LEARNING}

To describe how a robot can acquire skills to perform tasks such as motor coordination, collision detection, and color classification, three general approaches can be distinguished. In the black box approach, a robot automatically and autonomously acquires the desired skills without any prior assumptions on the environment using machine learning methods that are part of its software system. The robot researcher does not need to provide the robot with a partial solution. To indicate the converse of black box, we use the term "white box." That is, for a white box approach, a complete mathematical model of the robot and its environment can be developed and no machine learning is required. The robot is explicitly programmed to perform the desired task. All parameters are "set by hand," that is, the robotics researcher determines them individually using empirical tests and intuition. In the intermediate situation, the gray box approach, a partial model of the environment and the desired action sequence is available. A machine learning algorithm is employed to fine-tune the parameters of the sequence and to refine or optimize the robot's behavior [36]. The gray and black box approaches describe what is meant by robot learning-the application of machine learning methods to robotics [22], [29], [32]. In practice, at RoboCup, all machine learning approaches belong to the gray box category.

There are a number of practical reasons that make the application of machine learning methods to robotics challenging [22], [71], [73]:

1) High noise levels: Hardware limitations (for example, low camera resolution) often lead to high levels of noise in the data.

2) Stochastic actions: Interaction with the real world requires that robots cope with situations for which they are not prepared. This can lead to unexpected actions.

3) Time and material constraints: Learning must be achieved in a relatively small number of training epochs that depend on how fast the real-world robot can act.

4) Real-world real-time requirements: Many real-world situations require that the robot acts/reacts quickly, i.e., it must be able to process data in real-time. Suitable learning or adaptive methods must take this into account.

5) Task complexity: Depending on the complexity of the task (e.g., a quadruped walk is extremely complex), simulations or exact (white box) control models are, in many cases, not possible or inefficient, that is, online training must be conducted with the real robot.

The complexity of many real-world robotics tasks has naturally led to the use of complicated white box models. Through extensive empirical testing, robotics researchers try to understand the system and gain some insight into the parameters of the algorithms used. Parameters may, then, be chosen by hand.

Only recently, the robotics community has become more open to the suggestions from machine learning researchers to employ learning algorithms (gray box approach) so that robots could be trained on selected aspects of a task and certain parameter sets could be automatically tuned [28], [62], [98]. This allows for larger parameter spaces and better fine-tuning. The potential improvements and advantages that robotics research can gain by incorporating suitable machine technology are huge.

If robotics and machine learning wish to marry, then there are not only the above-mentioned challenges on the robotics side, which machine learning has to cope with, but there are also typical characteristics of the machine learning methodology that are not easy to deal with for robotics:

1) Bias and parameter tuning: Many sophisticated machine learning methods (for example, reinforcement learning) are themselves not understood well enough to be always optimally applicable in the first trial on a real-world robotics platform. They often require setting and tuning of critical learning parameters ("magic numbers") and biases without which the algorithms typically would not perform optimally or would not converge in acceptable time. Often only, experts with sufficient experience in using a particular type of model or algorithm have a chance to gain some immediate advantage from its application.

2) Long training times and poor convergence rates: A realworld robotics research project typically cannot afford to 
investigate an algorithm's behavior in long training and evaluation runs. To be of interest for robotics, the algorithms must come with practically useful estimates of convergence rates and training times. Research into reducing the training times has become a hot topic for real-world robotics, and recently, methods such as model-based reinforcement learning, learning by imitation, or behavioral cloning have been proposed and tested on tasks such as learning helicopter and fixed-wing aircraft control [17], [53], [83].

3) Transparency and interpretability of learning parameters: Diligent robotics researchers must be very careful about the transparency and control of the tools and methods employed. Only then can they keep a tight control over the behavior of a complex robotics system that is necessary to avoid the hardware damage. For efficient robot learning, the researchers would have to build domain knowledge into a gray box approach, and to facilitate this, the learning method, its parameters, and biases should have an interpretable meaning.

For a successful and an efficient use of machine learning technology in robotics, future research is, therefore, advised to address explicitly the practicability of machine learning algorithms for robotics.

\section{ENVIRONMENT OF THE FOUR-LEGGED LEAGUE AND THE AIBO ROBOT PLATFORM}

In the four-legged league, teams must use a hardware platform that is fixed by the rules. This is in contrast to the other robot leagues of RoboCup in which the teams construct their own robots. Essentially, this means that the four-legged league becomes a software-based competition, and therefore, this league also provides a stable and comparable platform for implementing machine learning on physical robots. The currently allowed hardware consists of several different models of Sony AIBO robots: the ERS-210, ERS-210a, and the newer ERS-7 models. All allowed models have 64-bit MIPS processors with clock speeds of $192 \mathrm{MHz}$ (ERS-210), $384 \mathrm{MHz}$ (ERS-210a), and $576 \mathrm{MHz}$ (ERS-7). Note that the ERS-210 and ERS-210a are identical apart from their processors, so we will only describe the physical specifications of the latter. The robots are programmed in $\mathrm{C}++$ using Sony's OPEN-R software development kit (see the OPEN-R website, openr.aibo.com) [35], [59]. The ERS210a measures (width $\times$ height $\times$ length) $154 \mathrm{~mm} \times 266 \mathrm{~mm}$ $\times 274 \mathrm{~mm}$, while the ERS-7 is slightly larger at $180 \mathrm{~mm} \times$ $278 \mathrm{~mm} \times 310 \mathrm{~mm}$. The ERS-210a weighs approximately $1.4 \mathrm{~kg}$, while the ERS-7 is $1.7 \mathrm{~kg}$. The robots are autonomous, but can communicate through wireless LAN (IEEE 802.11b) with the other robots on their team. Wireless communication was introduced into the competition in 2002.

Approximate specifications of different AIBO models used at RoboCup during the years 2000-2004 are summarized in Table I. Please note that the details collected from different team reports, Sony's webpages, and our own experience, did not always coincide. Information regarding the robot hardware used in the first few years of the league is not readily avail-
TABLE I

SPECIFICATIONS OF DIFFERENT MODELS OF THE SONY AIBO ROBOT AS USED IN THE FOUR-LEGGED LEAGUE OF ROBOCUP

\begin{tabular}{|c|c|c|c|c|}
\hline Model & ERS-110 & ERS-210 & ERS-210A & ERS-7 \\
\hline clock & - & $192 \mathrm{MHz}$ & $384 \mathrm{MHz}$ & $576 \mathrm{MHz}$ \\
memory & $8-16 \mathrm{MB}$ & $32 \mathrm{MB}$ & $32 \mathrm{MB}$ & $64 \mathrm{MB}$ \\
\hline camera & CCD & CMOS & CMOS & CMOS \\
pixels & $176 \times 120$ & $176 \times 144$ & $176 \times 144$ & $208 \times 160$ \\
frames & 30 & 25 & 25 & 30 \\
\hline second & 2000 & $2001-2004$ & $2003-2004$ & 2004 \\
\hline years & \multicolumn{3}{|c}{} \\
\hline
\end{tabular}

able, and the teams seem to interpret hardware parameters in different ways. We have also not included specifications about any prototype robots (for example, DRX-720 or MUTANT) that were used before 2000 [33], [34], [36]. The soccer rules in the four-legged league of RoboCup are only loosely based on real soccer, but the objective of the game is identical. Before 2002, a team consisted of three robots playing on a field of size $180 \mathrm{~cm}$ $\times 280 \mathrm{~cm}$ surrounded by white walls. In 2002, the field size was increased to $270 \mathrm{~cm} \times 420 \mathrm{~cm}$ and each team could, now, have four robots including the goalkeeper. The green playing surface itself is carpeted to protect the robots and allow a better grip. The ball is orange in color. Colored goals and corner beacons facilitate localization via the robot's color camera. More detailed rules and specifications of the environment are available at the RoboCup Legged League website www.tzi.de/4legged/. For RoboCup 2005, the field was further enlarged to $4 \mathrm{~m} \times 6 \mathrm{~m}$, the field boundaries were removed, and several other smaller rule changes were introduced.

\section{PRINCIPAl MACHINE LEARNING TASKS IN THE FOUR-LEGGED LEAGUE}

Machine learning methods can potentially be applied to many tasks in the four-legged league, including vision, localization, locomotion, and behavior. So far, however, machine learning has been used primarily for color classification in vision and to improve locomotion.

\section{A. Color Classification}

Robot vision systems are often required to identify landmarks relevant to the operation of the robot. In some cases, color alone can be used to identify landmarks. For other objects and landmarks, edge detection and shape recognition techniques can be used.

Currently, color is the primary criterion used to identify landmarks and objects on the four-legged league soccer field. Color classification is, therefore, a critically important part of the vision system. Generally speaking, color classification on AIBO robots [16], [92] is performed by using a precomputed table (a color table) that maps raw color information from the YUV color space into a small set of colors of interest to the robot. Colors of interest to the robot are often termed classified colors. Typically, clumps of classified color in the image are formed into "blobs." These steps are illustrated in Fig. 2. Blobs are, then, processed by various ad hoc techniques to determine which objects appear in the image. 

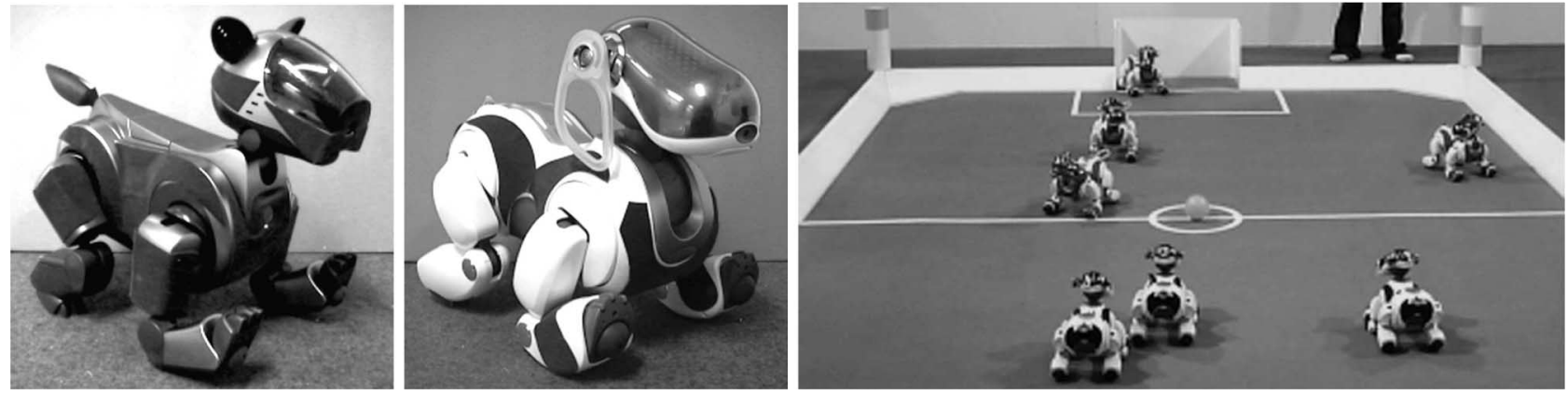

Fig. 1. (Left) Dark gray robot is the Sony ERS-210 model first introduced in 2001. (Middle) White robot is the newer Sony ERS-7 robot that has been in use since 2004. Both robots are shown wearing a blue uniform. (Right) Robots preparing for a kick-off in a game at RoboCup 2004.
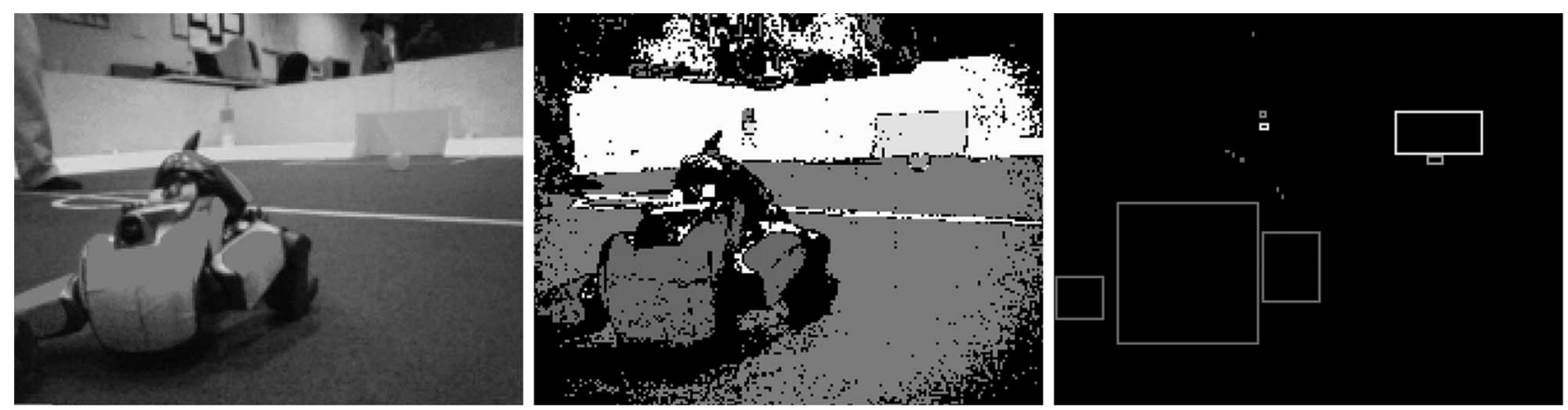

Fig. 2. Color classification process on a Sony AIBO robot. (Left) Original, unprocessed image obtained from the robot's camera. (Middle) Same image after color classification has been performed. (Right) Colored blobs that have been formed based on the color classified image. (For printing, colors have been converted into grayscale.)

Since the robot is extremely reliant on color for object detection, a new color table has to be generated after any change in the lighting conditions. This is usually a manual task that requires a human to capture hundreds of images and assign a color label on a pixel-by-pixel basis. It takes several hours to construct a new color table using this manual method, yet the table will still contain holes-unmarked points that are surrounded (or almost surrounded) by marked points of a particular colorand classification errors. Several machine learning algorithms are currently in use by RoboCup teams in order to reduce the classification errors and speed up the process. We address these further in Section VI.

\section{B. Walk Optimization}

The majority of teams in the legged league use an omnidirectional parameterized walk inspired by the work of Hengst et al. [46]. This original walk was commonly known as "PWalk" and some of its characteristics had been adopted by other teams when they developed their own walk engine. In all these walks, the end of each paw is commanded to follow a trajectory with inverse kinematics used to calculate the joint angles required to achieve the positions.

The optimization of the vector of walk parameters has become one of the primary applications areas of machine learning in the four-legged league. Table II gives descriptions of 17 similar parameters, as they were used in PWalk. Eight of these parameters affect the stance of the robot (front and back are
TABLE II

DESCRIPTION OF PWALK PARAMETERS (LOOSELy BASED ON [46])

\begin{tabular}{|l|l|}
\hline$h F / h B$ & Height of front/back hip above the ground $(\mathrm{mm})$ \\
$f s O / b s O$ & Sideways distance between shoulder and paw $(\mathrm{mm})$ \\
$f f O / b f O$ & Distance of the paw from shoulder to front $(\mathrm{mm})$ \\
$f d H / b d H$ & Max height the paw will be lifted off the ground $(\mathrm{mm})$ \\
\hline walkType & Defines the type or walk action to be used (int) \\
PG & Time taken for a step in (0.008 second units) \\
Forward & Distance the robot should walk forwards in step $(\mathrm{cm})$ \\
Turn & Angle (positive) the robot should turn (degrees) \\
Left & Distance to move left during the step ( $\mathrm{cm}$ ) \\
\hline hType & Type of head movement: none, relative, absolute (int) \\
tilt & Effects the up/down movement of the head (degrees) \\
pan & Effects the left/right movement of the head (degrees) \\
mouth & Angle to open the mouth (degrees) \\
\hline
\end{tabular}

shown together), five parameters control the type, size, direction, and speed of each step, and four parameters control the movement and position of the head.

\section{Learning of Team Behavior}

In contrast to some of the other leagues, for example, the simulation league, there is a lack of machine learning applied to team behavior in the four-legged league. This is surprising, since many researchers in this league come from a machine learning background. One possible reason for this is that against common sense (soccer expert) intuition, team behavior was rarely of critical importance in match play: low-level skills were still the main differentiating factor between most teams in the league. 


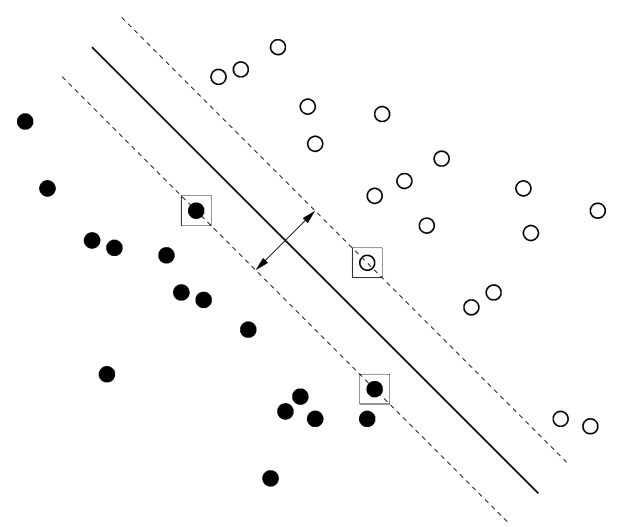

Fig. 3. Maximum margin classifier. Separating hyperplane where the emphasized inputs are support vectors.

It may be feasible for four-legged league teams to employ algorithms from other leagues (particularly simulation [109] and small size [14], [15]), although it is somewhat questionable as to whether these methods will transfer to the four-legged environment. In particular, the complexity of the construction of the four-legged league robots makes a sufficiently accurate simulation of the robots and their interaction with the environment difficult.

\section{Localization and World Modeling}

In the four-legged league, the primary sensor information comes from color vision that is very noisy. For localization, the robots can use estimates of the location of the colored corner beacons, the colored goals, and eventually, the white field lines. Kalman filters and particle filters are, so far, the dominating techniques for localization and are used by most teams of the four-legged league; see, for example, [66] and [74].

\section{How the Nubots HAVE EMPLOYED Machine LEARNING}

Machine learning methods were incorporated into the NUbots' software system only if there were strong indications that it would have advantages over a direct (white box) approach. We describe two examples.

\section{A. One-Class Classification With Support Vector Machines (SVMs)}

SVMs emerged from the field of statistical learning theory [13], [23], [89], [115], [116]. They are, now, commonly employed for tasks such as classification of handwriting and faces [101]. In their simplest version, SVMs can be described as maximum margin classifiers for binary classification (Fig. 3). This version works only on linearly separable data by selecting the hyperplane that separates the two classes by the largest margin [25]. A natural extension of the SVM algorithm to unlabeled data was proposed by Schölkopf et al. [102], who further noted that the new method should have abundant practical applications and could be regarded as an easy-to-use black box method as soon as questions like the selection of kernel parameters have been solved. In the one-class SVM approach, the data is im- plicitly mapped into a high-dimensional feature space where a separating hyperplane is calculated via a kernel and quadratic programming. The hyperplane is optimized to separate the training data with maximal distance from the origin while the number of outliers is bounded by some parameter $0<\nu \leq 1$.

Quinlan et al. [96], [97] applied SVMs to the task of color classification with AIBO robots. An individual one-class SVM was created for each color label. Scalable, tight-fitting cluster boundaries were obtained for each color cloud in YUV space (see Fig. 4). The results of this approach were superior to a previous approach using ellipse fitting [97]. The technique was also applied to the task of collision detection [95], where the one-class SVM is employed as a novelty detection mechanism. In this implementation, each training point is a vector containing 13 elements. These include five walk parameters, along with a sensor reading from the abductor and rotator joints on each of the four legs. The training set is generated by having the robot behave normally (takes approximately $10 \mathrm{~min}$ ) on the field but with the stipulation that all collisions are avoided. Upon training, the SVMs decision function will return +1 for all values that relate to a "normal" step, and -1 for all steps that contain a fault. A trained classifier analyzes the online stream of joint data measurements in samples of ten consecutive data points. If more than two points in one sample are classified as -1 , a collision is declared to be detected.

\section{B. Evolutionary Hill Climbing for Speed Optimization}

Each of the robot's legs follow a trajectory (or locus) in threedimensional coordinate space. The model includes PID values and allows independent loci for the front and back legs. Each locus is parameterized so that a large variety of suitable shapes are possible. Since quadruped locomotion has complex dynamics, the interpretation and tuning of 20-100 walk parameters was impossible by hand and a modified version of a $(1+1)$ evolution strategy was applied to optimize the walk parameters for speed [96].

For our walk engine, the parameters to be tuned are defined by a vector $\theta$ consisting of 11 walk parameters (turn and strafe are excluded from the learning) and the critical points defining an arbitrary locus shape (40 parameters). Each parameter is randomly set to an initial value; for our task, we make sure this initial vector is feasible (i.e., it is the one that will cause the robot to move in the required direction).

After a few hours of training, the learning approach resulted in an about $20 \%$ increase in walking speed over the speed achieved in 2002. At that particular time, walks with speeds up to almost $30 \mathrm{~cm} / \mathrm{s}$ were the fastest walks ever obtained for the AIBO ERS-210(A) within the four-legged league [64]. Upon receiving the ERS-7, we ran the learning algorithm on the new robot from a set of parameters that were developed on the ERS-210 robot. We managed to learn walks with an approximate speed of $41 \mathrm{~cm} / \mathrm{s}$ (the initial speed was below $25 \mathrm{~cm} / \mathrm{s}$ ). An example learning curve of this speed optimization process can be seen in Fig. 5. 


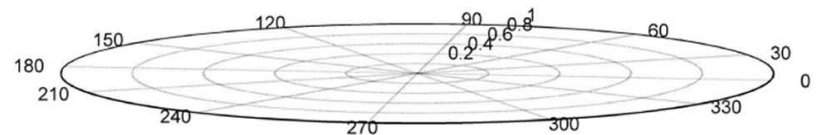

(a)

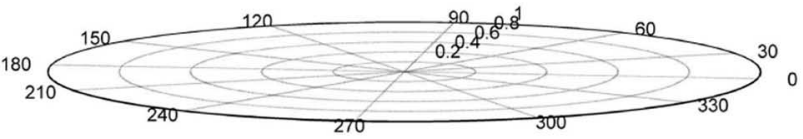

(c)
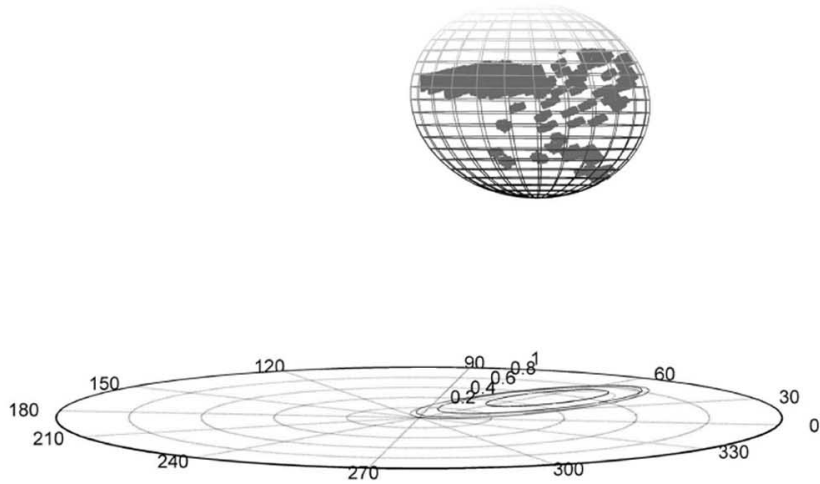

(b)

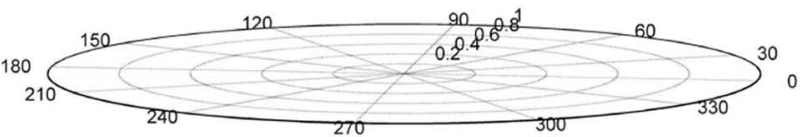

(d)

Fig. 4. Color classification. (a) Points manually classified at white. (b) Ellipsoid fitted to these white points. (c) Loose fit with one-class SVM technique, $\nu=0.025$ and $\gamma=10$. (d) Tight fit with one-class SVM technique, $\nu=0.025$ and $\gamma=250$.

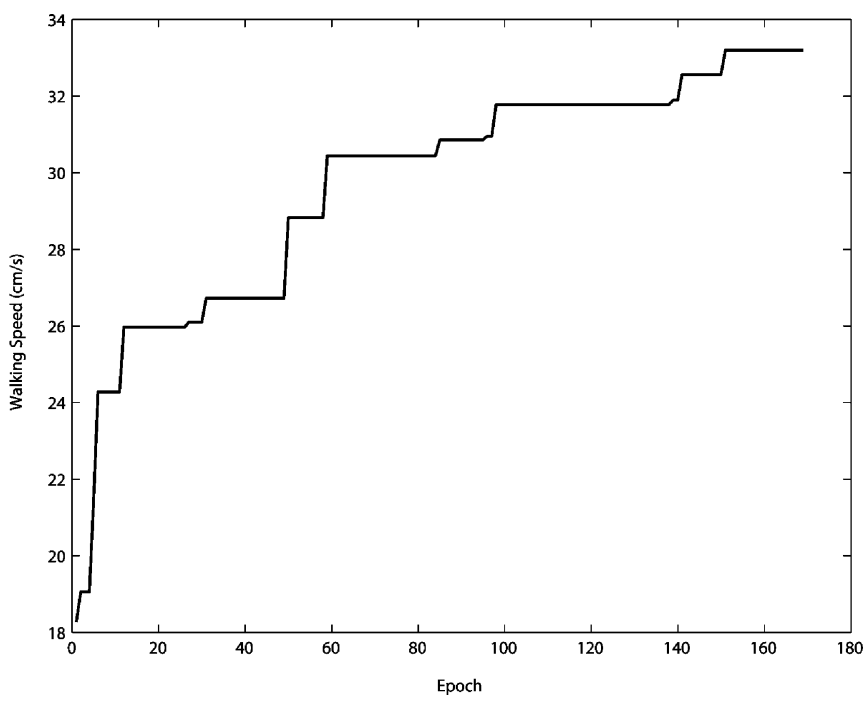

Fig. 5. Example of speed improvement obtained during approximately $1 \mathrm{~h}$ of training.

\section{MACHINE LEARNING IN THE FOUR-LEGGED LEAGUE}

The following review includes publications that contain information about the use of machine learning techniques in the Sony four-legged league of RoboCup 1998-2004. We primarily focus on the RoboCup Symposium proceedings [8], [12], [54], [82], [90], [105], [117]. However, in cases when we are aware of the use of machine learning methods in the four-legged league and the results have been published, for example, in the team reports, the team description papers (TDPs), or other publications, then we included them as well. As a symptom of the interdisciplinary character of RoboCup, many of the relevant publications are not specialized on machine learning. They often only briefly indicate when a machine learning method was applied without giving details of the algorithms, performance results, or comparisons with alternative approaches. Consequently, large parts of the following survey had to remain restricted to showing chronologically how the application of machine learning developed within the four legged league from 1998 to 2004 and only for selected publications some details and discussion of the approach could be included.

\section{A. Paris 1998}

In 1998, the four-legged league was an exhibition league by Sony and was composed of three teams from Carnegie Mellon University (CMU), Osaka, and Paris. At this early stage, expectations into robot learning were high and machine learning approaches were implemented for critical areas such as color classification, localization, and behavior acquisition [118].

The team from CMU used supervised learning on 20 training images based on a conjugate gradient descent technique to determine thresholds for classification in YUV color space [119]. For localization, they employed a Bayesian probabilistic approach [118]. 
The team from Osaka University utilized a behavior training mechanism: a human controlled the robot playing soccer, while all of the sensory data and the corresponding action performed by the human trainer were recorded. The C4.5 algorithm [94] was, then, used to extract the rule sets for performing various actions such as shooting.

However, it soon became clear that these tasks were extremely challenging and more research into robot learning would be required before satisfactory results could be expected.

\section{B. Stockholm 1999}

The year 1999 saw the four-legged league become an official RoboCup league. The number of teams increased to nine.

The University of Tokyo's team attempted to use a selforganizing map to "kick the ball where the robot wants to." They also investigated how to train two neural networks with backpropagation to calculate ideal head pan and tilts depending on the position of the ball [63].

Instead of performing the complex calculations of a global self-localization method, the team from Osaka University [80] developed a technique for using decision trees and prediction trees to observe the beacons, the goals, and the ball efficiently, and then, without calculating explicit positions, to decide directly which actions to take. They restricted the action space to a small number of elementary actions. The decision and prediction trees of their probabilistic action selection used the ID3 [93] information criterion [77].

The University of New South Wales' (UNSW) entry used a 2-D polygon growing algorithm to learn how to classify colors in a 2-D color space [27], [68].

\section{Melbourne 2000}

In Melbourne, the four-legged league expanded to include 12 teams. The team from UNSW showed superior performance in all its matches. Its success was partially due to a new and fast localization method that employed a stochastic gradient descent learning algorithm for incremental position updates [88]. Given the robot's position and heading in the current world model and a newly perceived position, the algorithm updated the current position and heading variables by moving them in small steps in direction toward a newly perceived position. For the method to calculate the perceived position and to perform its updates, it was sufficient if only one landmark at a time was visible. This is important because the AIBOs have a very narrow field of view. The update rate can be as high as the frame rate. With each frame, the learning algorithm's step size was varied depending on the landmark-associated decaying confidence parameters [27]. For color classification, the UNSW team extended their polygon growing algorithm from previous year to account for all three dimensions of the color space [45].

The team from McGill University employed a nearest neighbor interpolation method in YUV color space to assist in color table generation for color classification [72]. This approach allowed them to limit the necessary sample size for "color training" to 30 pictures that reduced the time required for vision calibration.

\section{Seattle 2001}

In 2001, the number of four-legged league teams increased from 12 to 16. The Essex Rovers team from the U.K. developed an evolutionary approach to allow their fuzzy-logic-based behavior controller to learn [39]. They also investigated [49]-[51] the use of neural networks for color detection tables. Their aim was to adapt to changing lighting conditions through variable threshold prediction in YUV space. Their approach was based on a method presented previously by the UNSW team.

In 2001, the UNSW team changed its method for color classification [19], and switched from the previously used polygon growing algorithm to the C4.5 decision tree algorithm [94].

The team of Osaka University mentions [79] that they made use of a genetic algorithm for tuning certain motion parameters. Team Cerberus (a joint team from Bulgaria and Turkey) implemented both decision trees and multilayer perceptrons for color classification as well as a genetically trained fuzzy neural network for behavior control [6].

\section{E. Fukuoka 2002}

At Fukuoka, Japan, the number of teams in the four-legged league increased to 19 . The UNSW team discontinued their use of C4.5 generated decision trees for color classification and switched to a nearest neighbor learning technique [120].

The University of Washington team [24] mentioned they had adopted decision trees for color cluster generation in YUV space. Their main focus, however, was on state estimation and world modeling, where they used particle filters to estimate the robots' positions and Kalman filters to trace the ball [42]. They were able to track the position of the robot using only 30 samples with an accuracy of the position estimates of about $10 \mathrm{~cm}$ on average. After the robot was picked up and placed back onto the field at a new location, it took them less than $2 \mathrm{~s}$ to relocalize the robot [24].

The Essex team continued its earlier experiments on behavior learning with fuzzy logic controllers, which allowed the robot to use the information from the camera to approach the ball and shoot at the goal. $\mathrm{Gu}$ and $\mathrm{Hu}$ [40] employed a combination of reinforcement learning [10] and evolutionary computation to learn refinements of the initially handcrafted parameters of their fuzzy logic controller architecture.

Dahm and Ziegler [26] from the German Team envisioned how evolutionary computation could improve localization. Genetic programming allowed them to increase the robots' walking speed to over $20 \mathrm{~cm} / \mathrm{s}$. They proposed that robustness and reliability of the walk could be improved using a multiobjective fitness function. The resulting more reliable odometry together with the improved vision and inter robot communication would lead to an increased accuracy within their Bayesian probabilistic approach to localization.

\section{F. Padova 2003}

At RoboCup 2003, in Italy, the league expanded to 24 teams. For the task of color classification, a variety of machine learning 
techniques were used by different teams. In 2003, Team Cerberus [5] and the UNSW team [20] both decided to employ standard decision tree approaches using the C4.5 algorithm [94]. The University of Texas at Austin team made use of a basic nearest neighbor scheme to learn how to classify colors [106]. The team from Griffith University implemented covering algorithms to learn decision lists to perform color classification [7]. The NUbots demonstrated, for the first time, that SVMs [13], [89], [101], [115] can be implemented on AIBOs to achieve refined clustering results in color space [96], [97]. Although the teams employed a variety of different methods, and accordingly, obtained classification results of different quality, it became clear that sophisticated object recognition with the AIBO camera not only depended on good color classification but other components of the vision system needed to be improved as well.

Researchers associated with the team from Essex, U.K., proposed an adaptive color segmentation algorithm with the aim to be able to adjust to different lighting conditions. In their pilot experiments [70], they employed self-organizing maps for color segmentation, and similar to that in previous years, an artificial neural net with supervised learning for adaptive threshold selection.

The team from the University of Chile (UChile) applied machine learning to a slightly different but an important aspect of the object recognition task. They developed a system for automated selection and tuning of rules for the detection of the ball, the landmarks, and the goals [125]. The system employed a genetic algorithm, a specifically adapted fitness function, and supervised learning on a set of about 180 preclassified images to evolve successful recognition rules.

The rUNSWift team began using a multidimensional optimization method to improve their straight-line walking speed [20], [57], [100]. Their walk engine implemented, similar to that in the previous year [46], a trot gait where diagonally opposite legs were synchronized and the two pairs of synchronized legs were $180^{\circ}$ out-of-phase. Each of the robot's feet followed a trapezoidal trajectory that was defined by its four corner points each of which could be displaced in three dimensions. Two independent trajectories were used, one for the front legs and one for the back legs. With these constraints, the problem could be represented as minimization over a 24-dimensional search space. Starting from a well-selected set of search directions [57], the rUNSWift team employed Powell's multidimensional directional set optimization method [91] that searches along each of these 24 directions separately. UNSW's researchers demonstrated, on the soccer fields in Padova, how to evaluate the different-walk-parameter settings by measuring the time required by the physical AIBO robot to run across the field between two opposite beacons at the sidelines. Although the speed achieved by UNSW's initial experiments was limited to $27 \mathrm{~cm} / \mathrm{s}$, it was demonstrated that the problems of hardware exhaustion, suboptimal results, and low efficiency, as reported in the early studies of Hornby et al. [47], [48] (cf., Section VII), could be overcome by narrowing down the search space, using a good walk engine and well-selected initial walk parameters.

\section{G. Lisbon 2004}

Impressed by the practicality of UNSW's walk learning experiments in 2003, the teams from the University of Texas at Austin [64], [65], [108], the University of Newcastle in Australia [96], Carnegie Mellon University [21], Kyushu University [52], and the German Team [99] developed their own walk optimization techniques. Some of the teams pushed the ERS-210s to walk with speeds of about $30 \mathrm{~cm} / \mathrm{s}$ and the new ERS-7s with speeds of about $40 \mathrm{~cm} / \mathrm{s}$. The preferred algorithm was simple reinforcement learning based on evolutionary algorithms. Most teams adopted a method for fitness evaluation as previously used by Hornby et al. [47], [48] or UNSW [20], [57], [100], which measured the time required by the robot to walk across a fixed distance between two colored landmarks. The German team [99] employed a different fitness evaluation that incorporated the robot paws' touch sensors to determine the time for which the robot's paws had ground contact while making a step as well as readings from the robot's acceleration sensors to minimize vibrations of the robot while walking. As documented by Kohl and Stone [64], most teams achieved comparable results and improved clearly over the maximum speed achieved by UNSW in the previous year [20], [57], [100].

Fidelman and Stone [31] built on the experience from walk learning and approached the task to let the ERS-7 learn grasp the ball. The robot had to learn to approach the ball and to control it under its chin to have it ready for a kick. Signals from the infrared range sensor on the robot's chest were used to provide the learning algorithms with a binary reward signal (ball capture $=1$; failure $=0$ ). Fidelman and Stone employed algorithms that had been previously used for walk learning and found that hill climbing, the amoeba algorithm, and policy gradient reinforcement learning led to comparable results. They reported that it took the robot about $3 \mathrm{~h}$, or roughly, 672 trials to increase an initial ball acquisition success rate from $36 \%$ to $64 \%$. This study was a fully autonomous robot learning experiment where all training was done on the physical robot [31].

In contrast to some of the previously discussed studies that aimed at fully autonomous learning on the robot, the UChile team developed a new AIBO simulator [124] that they used for learning the ball kicking behavior [123] and walking [126]. In their "Back to Reality" paradigm, they combined and co-evolved their learning systems in the simulator and on the physical robot. By minimizing the differences between fitness values obtained in the real and the virtual environment, the simulator was adjusted to match the real environment as much as possible. In pilot experiments [126], improvements in walking speed could be achieved by using a combination of genetic search for the simulator parameters and policy gradient reinforcement learning for associated learning on the physical robot. The fastest learned walk had a speed close to $25 \mathrm{~cm} / \mathrm{s}$, which is clearly less than the fastest walks achieved by some of the other teams in 2004. Zagal and Ruiz-del-Solar [124] claimed that the reason for this suboptimal result may have been the restrictive design of their walk engine.

While ball, goal, and beacon recognition are essential skills for a successful soccer play, the task of opponent and team 
player recognition was neglected by many teams during the early years of the league. Members of the German team [122] implemented, for test purposes, a robot recognition method based on C4.5 decision tree learning [94]. Their approach consisted of image segmentation, attribute calculation, classification, and analysis. One complete processing cycle took only $27 \mathrm{~ms}$ and could be run on the AIBO. The most time-consuming step was attribute calculation that involved a slow iterative end-point algorithm [30]. The classification using decision trees was the fastest component [122].

\section{MACHINE LEARNING ON AIBOS IN GENERAL}

Several universities and other research groups conducted studies involving machine learning on AIBOs that may not have been used in the competition code of the four-legged league but have value from a research point of view.

Among the first machine learning applications on the AIBO robots were studies by researchers from Sony Corporation who employed an evolutionary algorithm with crossover and mutation to develop gaits for a prototype of AIBO [47] and for the first consumer versions of AIBO [48]. Their walk engine had about 20 parameters that were evolved to obtain nonfalling gaits, which followed either a crawl, trot, or pace pattern. The experiments started from a hand-developed crawl gait of about $6 \mathrm{~cm} / \mathrm{s}$ and reached $17 \mathrm{~cm} / \mathrm{s}$ for a pace and $10.8 \mathrm{~cm} / \mathrm{s}$ for a trot. The evolutionary algorithm had a population size of 30 and ran for 11 generations, where each generation took about $1 \mathrm{~h}$ to be processed on the physical robot [47]. Later, experiments [48] extended the search space to find gaits that were effective on different types of surfaces. Hornby et al. [47] reported that several parts of the robot had to be replaced repeatedly throughout the long walk learning experiments. This was possible because the researchers at Sony had sufficient access to new robot parts. However, the high hardware demands acted as a deterrent for researchers outside Sony and it would take about three years until the evolution of walk parameters for walking speed optimization was successfully attempted by teams within the four-legged league (cf., Sections V-B, VI-F, and VI-G).

In 2002, Hardt and von Stryk [44] employed iterative numerical optimization methods to minimize various performance and stability objectives for gait generation using a model of the AIBO robot based on kinematic and kinetic data provided by Sony. The model consisted of a nine-link tree-structure multibody system with central torso, a head at a fixed position, and four two-link legs. Hardt and von Stryk [44] mentioned that some of their simulations initially aimed at speeds of $67 \mathrm{~cm} / \mathrm{s}$ and possibly an implementation on the real robot at RoboCup 2002. However, as later developments on this topic would show, robust walking with speeds of that magnitude were not realistic on the physical AIBO robot.

In the same year, researchers at Essex [38] conducted a study on evolutionary gait generation on a physical AIBO robot. A genetic algorithm was employed to optimize 13 parameters of their locomotion module in 50 generations with a population size of 20. An overhead camera determined the extent of the robot's movement over five steps. Gyro sensor readings to determine walk stability were included with the movement measure into a fuzzy-logic-based fitness evaluation. The very low number of steps that were used for movement measurements protected the hardware, but it was not a precise speed measure. This, their large parameter space, and possible constraints of their walk engine may explain why they only achieved a maximum speed of $11.7 \mathrm{~cm} / \mathrm{s}$ [38], which is slow compared to other approaches at the same time (cf., Sections V-B, VI-F, and VI-G).

In the initial years of the four-legged league, another important task was to implement a vision system that achieved good results under constant and defined lighting conditions. After several teams had implemented vision systems with satisfactory performance, it became apparent that most of them required long calibration times because they heavily relied on color recognition and were extremely sensitive to small changes in lighting conditions. The task of color constancy or illumination invariance, that is, to be able to compensate for changes in lighting conditions was recently approached by several groups associated with the four-legged league.

Schulz and Fox [103] proposed a two-level Gaussian model where a switching Kalman filter estimated lighting conditions at the upper level. Different filters were initialized using Gaussian priors. The latter were learned independently on collections of training images where images with similar lighting conditions were clustered using $k$-means clustering. Further, a RaoBlackwellized particle filter was employed to take the robot's location in account by maintaining a joint posterior over robot positions and lighting conditions.

Sridharan and Stone [104] approached the color constancy task by proposing a nearest neighbor algorithm where a set of hand-labeled images is used to train color cubes to map arrays of $128^{3}$ pixel values to one of the ten relevant colors. With the KLdivergence as a measure for comparing image distributions, they proposed a method that allows the robot to recognize and adapt to three discrete illumination conditions: bright, intermediate, and dark.

Among the labs that installed an additional overhead camera for research purposes above the four-legged league soccer field was the group associated with the UChile four-legged team. The UChile group employed a delta-rule-based online learning algorithm for behavior learning with an AIBO robot [85]. The learned task was to move three randomly placed plastic cylinders to new positions on the soccer field until they formed the shape of a triangle.

In addition to the studies mentioned so far, there were several other projects which demonstrated that machine learning on AIBOs was employed for a large variety of tasks outside the fourlegged league competition. For example, Mitsunaga and Asada [78] employed decision trees for sensor space segmentation. Dynamic programming [113] was adopted for motion planning by Fukase et al. [37]. Learning of simple sensorimotor tasks using a convolutional neural network that automatically combines color, luminance, motion, and auditory information was presented by Lee and Seung [69]. Gu et al. [41] from Essex aimed at using a genetic algorithm and transfer from a simulation environment to learn ball-chasing and position-reaching behaviors. An unsupervised technique for the autonomous simultaneous 
TABLE III

OVERVIEW OF PUbliCATIONS THAT REPORT ON THE USE OF DECISION TREES (DT), NEURAL NETWORKS AND SVMS (NN/SVM), EVOLUTIONARY COMPUTATION AND REINFORCEMENT LEARNING (EC/RL), OR OTHER MACHINE LEARNING METHODS ON AIBO ROBOTS

\begin{tabular}{|c|c|llll|c|}
\hline Year & \#Teams & DT & NN/SVM & EC/RL & Other & \#Pub \\
\hline 1998 & 3 & & & & {$[118][119]$} & 2 \\
\hline 1999 & 9 & & {$[63]$} & {$[\mathbf{4 7}]$} & {$[68]$} & 3 \\
\hline 2000 & 12 & {$[77]$} & {$[50]$} & {$[\mathbf{4 8}]$} & {$[45][72]$} & 5 \\
\hline 2001 & 16 & {$[6][19]$} & {$[51][49][69]$} & {$[6][39][79]$} & {$[69][88]$} & 8 \\
\hline 2002 & 19 & {$[24][\mathbf{7 8}]$} & & {$[26][\mathbf{3 7}][40]$} & {$[\mathbf{4 4}][\mathbf{5 6}]$} & 9 \\
& & & & & {$[\mathbf{3 8}][120]$} & \\
\hline 2003 & 24 & {$[5][20]$} & {$[70][96][97]$} & {$[20][\mathbf{4 1}][57]$} & {$[7][\mathbf{5 5}]$} & 12 \\
& & & & {$[96][100][125]$} & {$[106]$} & \\
\hline 2004 & 24 & {$[\mathbf{1 1 4}][122]$} & {$[43]$} & {$[21][31][\mathbf{3 4}]$} & {$[\mathbf{8 1}][\mathbf{8 5}]$} & 19 \\
& & & & {$[52][64][65]$} & {$[\mathbf{1 0 3}][\mathbf{1 0 4}]$} & \\
& & & & {$[\mathbf{6 7}][99][108]$} & {$[\mathbf{1 1 2}]$} & \\
& & & & {$[123][126]$} & & \\
\hline
\end{tabular}

calibration of action and sensor models was implemented on the ERS-7 by Stronger and Stone [112]. Vail and Veloso [114] used C4.5 for surface prediction and employed accelerometer data for velocity prediction using the $k$-nearest neighbor algorithm [75]. Kwok and Fox [67] employed least square policy iteration for learning sensing strategies that led to an improved goal scoring behavior in the four-legged league domain. Some possibilities of using nonlinear dimensionality reduction methods in the legged league domain were explored by Murch [81].

AIBOs became a popular platform for research in new aspects of robotics such as human-robot, animal-robot, or robot-robot interaction. Several of these projects have involved machine learning. Examples are robotic clicker training [56], experiments on neural learning for pointing gestures between two robots [43], or studies in curiosity-driven developmental robotics [55], [86], [87]. Researchers at Sony implemented AIBO's behavior control architecture using probabilistic state machines whose probabilities are modified using reinforcement learning through interaction with the user [34].

\section{DISCUSSION}

The survey of Section VI revealed that the use of machine learning in the four-legged league was limited but growing. Table III presents a combined chronological overview of projects using machine learning on AIBO robots in general and at the four-legged league competition. The references to general projects (from Section VII) are emphasized in boldface. Although a precise match of the year when the study was conducted and the year when the results were published was not always possible, a clear upwards trend of the use of machine learning on AIBOs is indicated in Table III. A dramatic increase in the use of machine learning can be observed in 2003. By then, evolutionary [9], reinforcement learning algorithms [11], [113], or other simple search algorithms [91] were used for parameter optimization, and it led to significant increases in walking speeds of the AIBO. Related approaches and spin-off studies by several competition teams and research groups then followed. These advancements in walking speeds through machine learning were primarily achieved by the more successful and experienced teams of the four-legged league. Mutual inspiration of ideas and comparison of results between these research groups is documented in the associated publications, for example, [57], [64], [65], [96], and [99].

It is agreed by many researchers in the field that, given the challenges presented in Section II, the successful application of, for example, evolutionary or reinforcement learning methods on AIBOs, to obtain results superior to hand-coding is a triumph. However, when compared with the very large amount of software and the vast array of algorithms produced by each team, machine learning still plays only a minor role. So far, only a few machine learning techniques appear to be commonly used by the four-legged league's robot programmers. The most prominent among them are the C4.5 decision tree algorithm [94], neural networks, SVMs, various simple clustering methods, and some basic evolutionary and reinforcement learning algorithms.

In the above-mentioned studies on walk learning, for example, it becomes apparent that most of the approaches employed very simple algorithms that are good for fast evaluation, as this is important for experiments where large numbers of iterations can be performed. However, the task of walk learning with AIBOs only allows small numbers of iterations but there is a plenty of time between the updates so that longer calculations with much more sophisticated algorithms could be performed. More sophisticated algorithms for this task, however, are not as well known or as "practical" as the basic algorithms. The design and application of more advanced algorithms that address this issue might be a direction for future research.

This indicates that for the roboticists of the four-legged league, the practicality of the machine learning method is an essential condition. "Practicality" means it has already been shown that the method works efficiently and a good implementation exists that is convenient to use and well documented. A machine learning approach was typically considered only if it promised to significantly improve a white box approach, or in situations where the latter was not feasible.

The growing use of machine learning in the four-legged league demonstrates that RoboCup is progressing according to its mission to foster research through a robot soccer competition [60]. This is corroborated by the observation that there is an increasing number of projects using machine learning on AIBO robots that appear to be spin-off projects associated with the competitions at RoboCup (see Section VII). In contrast to the application-oriented machine learning projects of the soccer competition, the spin-off projects tended to take 
method-oriented approaches and to investigate newer and more advanced machine learning methods or tasks.

\section{CONCLUSION}

RoboCup is an exciting initiative that accelerates research into intelligent robotics, multiagent systems, and robot learning. The four-legged league is important because it is the only real robot league at RoboCup where all the teams employ the same prescribed hardware, and therefore, can focus on software development and algorithm design.

For an evaluation of the use of machine learning in the fourlegged league and on AIBO robots, it is appropriate to distinguish between application-oriented projects of the competition teams and method-oriented studies of general research projects using AIBOs.

A chronological review showed that the number of publications per year on robot learning with AIBO robots increased from about 2 to 19 between 1998 and 2004. The use of machine learning in the four-legged league was initially limited, but later, it increased rapidly and led to impressive results.

Recently, Sony announced that it will cease the production of AIBO robots. Since AIBO robots have been such an excellent research platform, it is hoped that a suitable replacement will be found soon so that this fruitful initiative of software-focused research on robot learning, as it was developing within the Sony four-legged league, can successfully be continued. Sony is to be commended for the significant contributions AIBO robots have made in the development of machine intelligence research.

\section{ACKNOWLEDGMENT}

The first author would like to thank the RIKEN Brain Science Institute in Japan and AIFB at the University of Karlsruhe, Germany, for the hospitality during sabbatical. The authors are grateful to R. Middleton and CDSC for their support. Finally, they would like to thank the NUbots as well as other four-legged teams at RoboCup whose projects were the basis of this paper.

\section{REFERENCES}

[1] Sony Corp. (2005, Oct. 21). [Online]. Available: http://www.sony.net/ Products/aibo/

[2] Federation of International Robosoccer Association (FIRA). (2005, Jun. 1). [Online]. Available: http://www.fira.net/

[3] RoboCup. (2005, Jun. 1). [Online]. Available: http://www.robocup.org/

[4] RoboCup Special Interest Group (SIG) on Multiagent Learning. (2005, Oct. 21). RoboCup special interest group (SIG) on multiagent learning. [Online]. Available: http://sserver.sourceforge.net/SIG-learn/

[5] H. L. Akın, M. K. Baloğlu, H. K. Bağcı, S. Bayhan, C. Meriçli, D. Poslu, O. Sever, O. T. Yıldız, S. Argirov, B. Marinov, P. Pavlova, N. Shakev, J. Tombakov, and A. Topalov, "Cerberus 2003 team report," Boğaziçi Univ., Istanbul, Turkey, and Tech. Univ. Sofia, Sofia, Bulgaria, Tech. Rep., 2003.

[6] H. Akın, A. Topalov, and O. Kaynak, "Cerberus 2001 team description," in Lecture Notes in Computer Science, vol. 2377, A. Birk, S. Coradeschi, and S. Tadokoro, Eds. New York: Springer-Verlag, 2002, pp. 689-692.

[7] S. Anderson, K. Croaker, J. Dockter, V. Estivill-Castro, J. Fenwick, N. Lovell, and S. Seymon, "MiPAL team Griffith—Summary of our technology and implementation," Griffith Univ., Brisbane, Australia, Tech. Rep., 2003.

[8] M. Asada and H. Kitano, Eds., "RoboCup-1998: Robot Soccer World Cup II," in Lecture Notes in Computer Science, vol. 1604, New York: Springer-Verlag, 1999.
[9] T. Bäck, D. B. Fogel, and Z. Michalewicz, Eds., Handbook of Evolutionary Computation. Bristol, U.K: Inst. of Physics and New York: Oxford Univ. Press, 1997.

[10] A. G. Barto, R. S. Sutton, and C. W. Anderson, "Neuron-like adaptive elements that can solve difficult learning control problems," IEEE Trans. Syst., Man, Cybern., vol. SMC-13, no. 5, pp. 834-846, Sep. 1983.

[11] D. Bertsekas and J. Tsitsiklis, Neuro-Dynamic Programming. Belmont, MA: Athena Scientific, 1996.

[12] A. Birk, S. Coradeschi, and S. Tadokoro, Eds., "RoboCup-2001: Robot Soccer World Cup V," in Lecture Notes in Computer Science, vol. 2377. New York: Springer-Verlag, 2002.

[13] B. E. Boser, I. M. Guyon, and V. N. Vapnik, "A training algorithm for optimal margin classifiers," in Proc. 5th Annu. ACM Workshop Comput. Learn. Theory, D. Haussler, Ed. Pittsburgh, PA, Jul.1992, pp. $144-152$.

[14] M. Bowling, B. Browning, A. Chang, and M. Veloso, "Plays as team plans for coordination and adaptation," presented at the IJCAI Workshop Issues Design. Phys. Agents Dyn. Real-Time Environ.: World Modeling, Plan., Learn., Commun., Acapulco, Mexico, 2003.

[15] M. Bowling and M. Veloso, "Simultaneous adversarial multi-robot learning," in Proc. 18th Int. Joint Conf. Artif. Intell., Acapulco, Mexico, 2003, pp. 699-704.

[16] J. Bruce, T. Balch, and M. Veloso, "Fast and inexpensive color image segmentation for interactive robots," in Proc. 2000 IEEE/RSJ Int. Conf. Intell. Robots Syst. (IROS-2000), vol. 3, Oct., pp. 2061-2066.

[17] G. Buskey, J. Roberts, and G. Wyeth, "A helicopter named DollyBehavioural cloning for autonomous helicopter control," presented at the Australas. Conf. Robot. Autom., W. Friedrich and P. Lim, Eds., Aukland, Norway, 2002, 2002.

[18] S. K. Chalup and C. L. Murch, "Machine learning in the four-legged league," presented at the 3rd IFAC Symp. Mechatron. Syst., Sydney, Australia, Sep. 6-8, 2004.

[19] S. Chan, M. Sio, T. Volgelgesang, T. F. Yik, B. Hengst, S. B. Pham, and C. Sammut, "The UNSW RoboCup 2001 Sony Legged Robot League Team," in Lecture Notes in Computer Science, vol. 2377, A. Birk, S. Coradeschi, and S. Tadokoro, Eds. New York: Springer-Verlag: Springer-Verlag, 2002, pp. 39-45.

[20] J. Chen, E. Chung, R. Edwards, N. Wong, B. Hengst, C. Sammut, and W. Uther, "Rise of the AIBOS III-AIBO revolutions," Univ. New South Wales, Sydney, Australia, Tech. Rep., 2003.

[21] S. Chernova and M. Veloso, "An evolutionary approach to gait learning for four-legged robots," in Proc. 2004 IEEE/RSJ Int. Conf. Intell. Robots Syst. (IROS-2004), pp. 2562-2567.

[22] J. Connell and S. Mahadevan, Eds., Robot Learning. Norwell, MA: Kluwer, 1993.

[23] C. Cortes and V. Vapnik, "Support vector networks," Mach. Learn., vol. 20, pp. 273-297, 1995.

[24] Z. Crisman, E. Curre, C. Kwok, L. Meyers, N. Ratliff, L. Tsybert, and D. Fox, "Team description: UW Huskies-02," in Lecture Notes in Computer Science, vol. 2752, G. A. Kaminka, P. U. Lima, and R. Rojas, Eds. New York: Springer-Verlag, 2002.

[25] N. Cristianini and J. Shawe-Taylor, An Introduction to Support Vector Machines. Cambridge, U.K.: Cambridge Univ. Press, 2000.

[26] I. Dahm and J. Ziegler, "Adaptive methods to improve self-localization in robot soccer," in Lecture Notes in Computer Science, vol. 2752, G. A. Kaminka, P. U. Lima, and R. Rojas, Eds. New York: SpringerVerlag: Springer-Verlag, 2002, pp. 393-408.

[27] J. Dalgliesh and M. Lawther, "Playing soccer with quadruped robots," Comput. Eng. thesis, Sch. Comput. Sci. Eng., Univ. New South Wales, Sydney, Australia, 1999.

[28] J. Demiris and A. Birk, Eds., Interdisciplinary Approaches to Robot Learning. Singapore: World Scientific, 2000.

[29] M. Dorigo, "Introduction to the special issue on learning autonomous robots," IEEE Trans. Syt., Man, Cybern., vol. 26, no. 3, pp. 361-364, Jun. 1996.

[30] R. O. Duda and P. E. Hart, Pattern Classification and Scene Analysis. Hoboken, NJ: Wiley, 1973.

[31] P. Fidelman and P. Stone, "Learning ball acquisition on a physical robot," presented at the Int. Symp. Robot. Autom. (ISRA), Queretaro, Mexico, Aug. 2004.

[32] J. Franklin, T. Mitchell, and S. Thrun, "Robot learning," Mach. Learn. $J .$, vol. 23, no. 2/3, 1996.

[33] M. Fujita, "AIBO: Toward the era of digital creatures," Int. J. Robot. Res., vol. 20, pp. 781-794, 2001. 
[34] - "On activating human communications with pet-type robot AIBO," Proc. IEEE, vol. 92, no. 11, pp. 1804-1813, Nov. 2004.

[35] M. Fujita and K. Kageyama, "An open architecture for robot entertainment," in Proc. 1st Int. Conf. Autonom. Agents, 1997, pp. 435-442.

[36] M. Fujita and H. Kitano, "Development of an autonomous quadruped robot for robot entertainment," Autonom. Robots, vol. 5, no. 1, pp. 7-18, 1998.

[37] T. Fukase, Y. Kobayashi, R. Ueda, T. Kawabe, and T. Arai, "Real-time decision making under uncertainty of self-localisation results," in Lecture Notes in Computer Science, vol. 2752, G. A. Kaminka, P. U. Lima, and R. Rojas, Eds. New York: Springer-Verlag: Springer-Verlag, vol. 2752, 2002, pp. 375-383.

[38] D. Golubovic and H. Hu, "A hybrid evolutionary algorithm for gait generation of Sony legged robots," in Proc. 28th Annu. Conf. IEEE Ind. Electron. Soc., Sevilla, Spain, Nov. 5-8, 2002, pp. 2593-2598.

[39] D. Gu and $\mathrm{H}$. Hu, "Evolving fuzzy logic controllers for sony legged robots," in Lecture Notes in Computer Science, vol. 2377, A. Birk, S. Coradeschi, and S. Tadokoro, Eds. New York: Springer-Verlag: Springer-Verlag, 2002, pp. 356-361.

[40] - "Reinforcement learning of fuzzy logic controller for quadruped walking robots," presented at the 15th IFAC World Congr., Barcelona, Spain, Jul. 21-26, 2002.

[41] D. Gu, H. Hu, J. Reynolds, and E. Tsang, "GA-based learning in behaviour based robotics," in Proc. IEEE Int. Symp. Comput. Intell. Robot. Autom., vol. 3, Kobe, Japan, Jul. 16-20, 2003, pp. 1521-1526.

[42] J.-S. Gutmann and D. Fox, "An experimental comparison of localization methods continued," in Proc. IEEE/RSJ Int. Conf. Intell. Robots Syst., 2002, pp. 454-459.

[43] V. V. Hafner and F. Kaplan, "Learning to interpret pointing gestures: Experiments with four-legged autonomous robots," in Proc. NeuroBotics Workshop, G. Palm and S. Wermter, Eds., 2004, pp. 225-234.

[44] M. Hardt and O. von Stryk, "The role of motion dynamics in the design, control and stability of bipedal and quadrupedal robots," in Lecture Notes in Computer Science, vol. 2752, G. A. Kaminka, P. U. Lima, and R. Rojas, Eds. New York: Springer-Verlag: Springer-Verlag, 2002, pp. 206-223.

[45] B. Hengst, D. Ibbotson, S. B. Pham, J. Dalgliesh, M. Lawther, P. Preston, and C. Sammut, "The UNSW robocup 2000 Sony legged league team," in Lecture Notes in Computer Science, vol. 2019, P. Stone, T. Balch, and G. Kraetzschmar, Eds. New York: Springer-Verlag: Springer-Verlag, 2001, pp. 64-75.

[46] B. Hengst, S. Pham, D. Ibbotson, and C. Sammut, "Omnidirectional locomotion for quadruped robots," in Lecture Notes in Computer Science, vol. 2377, A. Birk, S. Coradeschi, and S. Tadokoro, Eds. New York: Springer-Verlag: Springer-Verlag, 2002, pp. 368-373.

[47] G. S. Hornby, M. Fujita, S. Takamura, T. Yamamoto, and O. Hanagata, "Autonomous evolution of gaits with the Sony quadruped robot," in Proc. 1999 Genetic Evol. Comput. Conf. (GECCO), vol. 2, W. Banzhaf, J. Daida, A. E. Eiben, M. H. Garzon, V. Honavar, M. Jakiela, and R. E. Smith, Eds. San Mateo, CA: Morgan Kaufmann, 1999, pp. 12971304.

[48] G. S. Hornby, S. Takamura, J. Yokono, O. Hanagata, T. Yamamoto, and M. Fujita, "Evolving robust gaits with AIBO," in Proc. IEEE Int. Conf. Robot. Autom. (ICRA-2000), pp. 3040-3045.

[49] H. Hu, D. Gu, D. Golubovic, B. Li, and Z. Lio, "Essex Rovers 2001 team description," in Lecture Notes in Computer Science, vol. 2377, A. Birk, S. Coradeschi, and S. Tadokoro, Eds. New York: Springer-Verlag: Springer-Verlag, 2002, pp. 697-700.

[50] H. Hu and D. Gu, "A multi-agent system for cooperative quadruped walking robots," presented at the IASTED Int. Conf. Robot. Appl., Honolulu, HI, Aug. 14-16, 2000.

[51] — , "Reactive behaviours and agent architecture for Sony legged robots to play football," Int.J.Indus. Robot, vol. 28, no. 1, pp. 45-53, Jan. 2001.

[52] J. Inoue, H. Aoyama, A. Ishino, and A. Shinohara. (2004). Jolly pochie 2004 in the four legged robot league. Dept. Inf., Kyushu Univ. 33, Fukuoka, Japan, Tech. Rep. [Online]. Available: http://www.i.kyushuu.ac.jp/JollyPochie/

[53] A. Isaac and C. Sammut, "Goal-directed learning to fly," in Proc. 20th Int. Conf. Mach. Learn., T. Fawcett and N. Mishra, Eds., Washington, DC, 2003, pp. 258-265.

[54] G. A. Kaminka, P. U. Lima, and R. Rojas, Ed., "RoboCup-2002: Robot Soccer World Cup VI," in Lecture Notes in Computer Science, vol. 2752. New York: Springer-Verlag, 2003.

[55] F. Kaplan and P.-Y. Oudeyer, "Motivational principles for visual knowhow development," in Proc. 3rd Epigenetic Robot. Workshop: Modeling Cogn. Dev. Robot. Syst. vol. 101, C. Prince, L. Berthouze, H. Kozima,
D. Bullock, G. Stojanov, and C. Balkenius, Eds., ser. Lund University Cognitive Studies Series, pp. 72-80, 2003.

[56] F. Kaplan, P.-Y. Oudeyer, E. Kubinyi, and A. Miklosa, "Robotic clicker training," Robot. Autonom. Syst., vol. 38, no. 3/4, pp. 197-206, 2002.

[57] M. S. Kim and W. Uther, "Automatic gait optimisation for quadruped robots," in Australasian Conf. Robot. Autom. (ACRA'2003), pp. 1-9.

[58] H. Kitano, Ed., "RoboCup-1997: Robot Soccer World Cup I," in Lecture Notes in Computer Science, vol. 1395. New York: Springer-Verlag, 1998.

[59] H. Kitano, M. Fujita, S. Zrehen, and K. Kageyama, "Sony legged robot for RoboCup challenge," in Proc. 1998 IEEE Int. Conf. Robot. Autom., vol. 3, May 16-20, pp. 2605-2612.

[60] H. Kitano, M. Asada, Y. Kuniyoshi, I. Noda, E. Osawa, and H. Matsubara, "RoboCup: A challenge problem for AI and robotics," in Lecture Notes in Computer Science, vol. 1395, H. Kitano, Ed. New York: SpringerVerlag, 1997.

[61] —_ "RoboCup: A challenge problem for AI," AI Mag., vol. 18, no. 1, pp. 73-85, 1997.

[62] A. Kleiner, M. Dietl, and B. Nebel, "Towards a life-long learning soccer agent," in Lecture Notes in Computer Science, vol. 2752, G. A. Kaminka, P. U. Lima, and R. Rojas, Eds. New York: Springer-Verlag, 2002.

[63] Y. Kobayashi and H. Yuasa, "Team ARAIBO," in Lecture Notes in Computer Science, vol. 1856, M. Veloso, E. Pagello, and H. Kitano, Eds. New York: Springer-Verlag, 2000, pp. 758-761.

[64] N. Kohl and P. Stone, "Machine learning for fast quadrupedal locomotion," in Proc. 19th Nat. Conf. Artif. Intell., 2004, pp. 611-616.

[65] - "Policy gradient reinforcement learning for fast quadrupedal locomotion," in IEEE Int. Conf. Robot. Autom., 2004, pp. 2619-2624.

[66] C. Kwok and D. Fox, "Map-Based Multi Model Tracking of a Moving Object," in Lecture Notes in Computer Science, vol. 3276, D. Nardi, M. Riedmiller, C. Sammut, and J. Santos-Victor, Eds. New York: Springer-Verlag, 2004.

[67] - "Reinforcement learning for sensing strategies," in Proc.IEEE/RSJ Int. Conf. Intell. Robots Systems (IROS-04), 2004, pp. 3158-3163.

[68] M. Lawther and J. Dalgliesh, "UNSW United," in Lecture Notes in Computer Science, vol. 1856, M. Veloso, E. Pagello, and H. Kitano, Eds. New York: Springer-Verlag, 2000, pp. 788-791.

[69] D. D. Lee and H. S. Seung, "Biologically inspired computation and learning in sensorimotor systems," in Proc. SPIE. Applications and Science of Neural Networks, Fuzzy Systems, and Evolutionary Computation IV, vol. 4479, B. Bosacchi, D. B. Fogel, and J. C. Bezdek, Eds. 2001, pp. 4-11.

[70] B. Li, H. Hu, and L. Spacek, "An adaptive color segmentation algorithm for Sony legged robots," in Proc. 21 st IASTED Int. Conf. Appl. Inform., Insbruck, Austria, Feb. 1-13, 2003, pp. 126-131.

[71] S. Mahadevan, "Machine learning for robots: A comparison of different paradigms," in Proc. Workshop Towards Real Autonomy, IEEE/RSJ Int. Conf. Intell. Robots Syst. (IROS-96), 1996.

[72] G. Marceau, "The McGill's red dogs legged league system," in Lecture Notes in Computer Science, vol. 2019, P. Stone, T. Balch, and G. Kraetzschmar, Eds. New York: Springer-Verlag, 2001, pp. 627630.

[73] M. Mataric and D. Cliff, "Challenges in evolving controllers for physical robots," Robot. Auton. Syst., vol. 19, no. 1, pp. 67-83, 1996.

[74] R. H. Middleton, M. Freeston, and L. McNeill, "An application of the extended Kalman filter to robot soccer localisation and world modelling," presented at the IFAC Symp. Mechatron. Syst., Sydney, Australia, 2004.

[75] M. Mitchell, An Introduction to Genetic Algorithms. Cambridge, MA: MIT Press, 1996.

[76] T. Mitchell, Machine Learning. New York: McGraw Hill, 1997.

[77] M. Mitsunaga and M. Asada, "Observation strategy for decision making based on information criterion," in Lecture Notes in Computer Science, vol. 2019, P. Stone, T. Balch, and G. Kraetzschmar, Eds. New York: Springer-Verlag, 2001, pp. 189-198.

[78] — "Visual attention control by sensor space segmentation for a small quadruped robot based on information criterion," in Lecture Notes in Computer Science, vol. 2377, A. Birk, S. Coradeschi, and S. Tadokoro, Eds. New York: Springer-Verlag, 2002, pp. 154-163.

[79] N. Mitsunaga, Y. Nagai, T. Ishida, T. Izumi, and M. Asada, "Baby Tigers 2001: Osaka Legged Robot Team," in Lecture Notes in Computer Science, vol. 2377, A. Birk, S. Coradeschi, and S. Tadokoro, Eds. New York: Springer-Verlag, 2002, pp. 685-688.

[80] N. Mitsunaga and M. Asada, "BabyTigers 1999: Osaka Legged Robot Team," in Lecture Notes in Computer Science, vol. 1856, M. Veloso, E. Pagello, and H. Kitano, Eds. New York: Springer-Verlag, 2000, pp. $762-765$. 
[81] C. L. Murch, "Dimensionality reduction on AIBO robots," Honours thesis, School Elect. Eng. Comput. Sci., Univ. Newcastle, Newcastle, Australia, Nov. 2004.

[82] D. Nardi, M. Riedmiller, C. Sammut, and J. Santos-Victor, Eds., "RoboCup-2004: Robot Soccer World Cup VIII," in Lecture Notes in Computer Science, vol. 3276. New York: Springer-Verlag, 2005.

[83] A. Y. Ng, H. J. Kim, M. I. Jordan, and S. Sastry, "Autonomous helicopter flight via reinforcement learning," in Advances in Neural Information Processing Systems 16, S. Thrun, L. Saul, and B. Schölkopf, Eds. Cambridge, MA: MIT Press, 2003.

[84] NIPS Conference. Advances in neural information processing systems. Cambridge, MA: MIT Press, Jun. 1998. [Online]. Available: http://nips.cc

[85] X. Olivares, J. Ruiz-del-Solar, and J. C. Zagal, "Online learning of an object manipulation behaviour for legged robots," in Proc. 1st IEEE Latin Amer. Robot. Symp. (LARS), Mexico City, Mexico, Oct. 28-29, 2004, pp. 42-47.

[86] P.-Y. Oudeyer and F. Kaplan, "Intelligent adaptive curiosity: A source of self-development," presented at the 4th Epigenetic Robot. Workshop, Genoa, Italy, 2004.

[87] P.-Y. Oudeyer, F. Kaplan, V. Hafner, and A. Whyte, "The playground experiment: Task-independent development of a curious robot," in Proc. AAAI Spring Symp. Workshop Dev. Robot., 2005, pp. 42-47.

[88] S. Pham, B. Hengst, D. Ibbotson, and C. Sammut, "Stochastic gradient descent localisation in quadruped robots," in Lecture Notes in Computer Science, vol. 2377, A. Birk, S. Coradeschi, and S. Tadokoro, Eds. New York: Springer-Verlag, 2002, pp. 447-452.

[89] T. Poggio and S. Smale, "The mathematics of learning: Dealing with data," Notices Amer. Math. Soc., vol. 50, no. 5, pp. 537-544, 2003.

[90] D. Polani, B. Browning, A. Bonarini, and K. Yoshida, Eds., "RoboCup 2003: Robot Soccer World Cup VII," in Lecture Notes in Computer Science, vol. 3020. New York: Springer-Verlag, 2004.

[91] W. Press, S. Teukolsky, W. T. Vetterling, and B. Flannery, Numerical Recipes in C: The Art of Scientific Computing, 2nd ed. Cambridge, U.K.: Cambridge Univ. Press, 1995.

[92] F. K. H. Quek, "An algorithm for the rapid computation of boundaries of run-length encoded regions," Pattern Recognit. J., vol. 33, no. 10, pp. 1637-1649, Oct. 2000.

[93] J. R. Quinlan, "Discovering rules from large collections of examples: A case study" in Expert Systems in the Microelectronic Age, D. Michie, Ed. Edinburgh, Scotland: University Press, 1979.

[94] -, C4.5: Programs for Machine Learning. San Mateo, CA: Morgan Kaufmann, 1993.

[95] M. J. Quinlan, C. Murch, R. H. Middleton, and S. K. Chalup, "Traction monitoring for collision detection with legged robots," in Lecture Notes in Artificial Intelligence, vol. 3020, D. Polani, B. Browning, A. Bonarini, and K. Yoshida, Eds., New York: Springer-Verlag, 2004.

[96] M. J. Quinlan, S. K. Chalup, and R. H. Middleton, "Techniques for improving vision and locomotion on the Sony AIBO robot," presented at the Australas. Conf. Robot. Autom. (ACRA'2003), Brisbane, Australia.

[97] _ "Application of SVMs for colour classification and collision detection with AIBO robots," in Advances in Neural Information Processing Systems 16 (NIPS'2003), S. Thrun, L. Saul, and B. Schölkopf, Eds. Cambridge, MA: MIT Press, 2004.

[98] M. Riedmiller and A. Merke, "Using machine learning techniques in complex multi-agent domains," in Perspectives on Adaptivity and Learning, Lecture Notes in Computer Science, I. Stamatescu, W. Menzel, M. Richter, and U. Ratsch, Eds. New York: Springer-Verlag, 2002.

[99] T. Röfer, "Evolutionary gait-optimization using a fitness function based on proprioception," in Lecture Notes in Computer Science, vol. 3276, D. Nardi, M. Riedmiller, C. Sammut, and J. Santos-Victor, Eds. New York: Springer-Verlag, 2004.

[100] C. Sammut, "Robot soccer: Science or just fun and games?," in Proc. Adv. Artif. Intell. 16th Australian Conf. AI (AI 2003), Lecture Notes in Artificial Intelligence, vol. 2903, T. D. Gedeon and L. C. C. Fung, Eds., pp. 12-23.

[101] B. Schölkopf and A. J. Smola, Learning With Kernels: Support Vector Machines, Regularization, Optimization, and Beyond. Cambridge, MA: MIT Press, 2002.

[102] B. Schölkopf, J. C. Platt, J. Shawe-Taylor, A. J. Smola, and R. C. Williamson, "Estimating the support of a high-dimensional distribution," Neural Comput., vol. 13, pp. 1443-1471, 2001.

[103] D. Schulz and D. Fox, "Bayesian color estimation for adaptive visionbased robot localization," in Proc. IEEE/RSJ Int. Conf. Intell. Robots Syst. (IROS-04), 2004, pp. 1884-1889.
[104] M. Sridharan and P. Stone,, "Towards illumination invariance in the legged league," in Robo Cup-2004: Robot Soccer World Cup VIII, Lecture Notes in Computer Science, vol. 3276, D. Nardi, M. Riedmiller, and C. Sammut, Eds. Berlin, Germany: Springer-Verlag, 2005, pp. 196-208.

[105] P. Stone, T. Balch, and G. Kraetzschmar, Eds., "RoboCup-2000: Robot Soccer World Cup IV," in Lecture Notes in Computer Science, vol. 2019. New York: Springer, 2001.

[106] P. Stone, K. Dresner, S. Erdoğan, P. Fidelman, N. Jong, N. Kohl, G. Kuhlmann, E. Lin, M. Sridharan, D. Stronger, and G. Hariharan, "UT Austin Villa 2003: A new RoboCup four-legged team," Univ. of Texas at Austin, Tech. Rep. 2003

[107] P. Stone, "Multiagent competitions and research: Lessons from RoboCup and TAC," in Lecture Notes in Computer Science, vol. 2752, G. A. Kaminka, P. U. Lima, and R. Rojas, Eds., New York: SpringerVerlag, 2002, pp. 224-237.

[108] P. Stone, K. Dresner, P. Fidelman, N. K. Jong, N. Kohl, G. Kuhlmann, M. Sridharan, and D. Stronger, "The UT Austin Villa 2004 RoboCup four-legged team: Coming of age," Dept. Comput. Sci., AI Lab., Univ. Texas at Austin, Tech. Rep. UT-AI-TR-04-313, Oct. 2004.

[109] P. Stone, R. S. Sutton, and G. Kuhlmann, "Reinforcement learning for RoboCup-soccer keepaway," Adapt. Behav., vol. 13, no. 3, pp. 165-188, 2005.

[110] P. Stone and M. Veloso, "Multiagent systems: A survey from a machine learning perspective," Auton. Robots, vol. 8, no. 3, pp. 345-383, 2000.

[111] _ _A survey of multiagent systems and multirobot systems," in Robot Teams: From Diversity to Polymorphism, T. Balch and L. E. Parker, Eds. Natick, MA: AK Peters, 2002, pp. 37-92.

[112] D. Stronger and P. Stone, "Simultaneous calibration of action and sensor models on a mobile robot," presented at the 2004 Int. Symp. Robot. Autom. (ISRA), Queretaro, Mexico, Aug. 2004.

[113] R. Sutton and A. Barto, Reinforcement Learning: An Introduction Cambridge, MA: MIT Press, 1998.

[114] D. Vail and M. Veloso, "Learning from accelerometer data on a legged robot," presented at the 5th IFAC/EURON Symp. Intell. Auton. Veh. (IAV2004), Lisbon, Portugal, Jul. 2004.

[115] V. N. Vapnik, The Nature of Statistical Learning Theory. New York: Springer-Verlag, 1995.

[116] - Statistical Learning Theory. New York: Wiley, 1998.

[117] M. Veloso, E. Pagello, and H. Kitano, Eds., "RoboCup-1999: Robot Soccer World Cup III," in Lecture Notes in Computer Science, vol. 1856. New York: Springer-Verlag, 2000.

[118] M. Veloso, W. Uther, M. Fujita, M. Asada, and H. Kitano, "Playing soccer with legged robots," in Proc. Int. Conf. Intell. Robots Syst. (IROS-98), 1998, pp. 437-442.

[119] M. Veloso and W. Uther, "The CMTrio-98 Sony legged robot team," in Lecture Notes in Computer Science, vol. 1604, M. Asada and H. Kitano, Eds., New York: Springer-Verlag, 1999, pp. 491-497.

[120] Z. Wang, J. Wong, T. Tam, B. Leung, M. S. Kim, J. Brooks, A. Chang, and N. Von Huben, "rUNSWift UNSW RoboCup2002 Sony Legged League Team," Univ. New South Wales, Kensington, NSW, Australia, Tech. Rep., 2002.

[121] T. Weigel, J.-S. Gutman, M. Dietl, A. Kleiner, and B. Nebel, "CS Freiburg: Coordinating robots for successful soccer playing," IEEE Trans. Robot. Autom., vol. 18, no. 5, pp. 685-699, Oct. 2002.

[122] D. Wilking and T. Röfer, "Realtime object recognition using decision tree learning," in Lecture Notes in Computer Science, vol. 3276, D. Nardi, M. Riedmiller, C. Sammut, and J. Santos-Victor, Eds. New York: Springer-Verlag, 2004.

[123] J. C. Zagal and J. Ruiz-del Solar, "Learning to kick the ball using back to reality," in Lecture Notes in Computer Science, D. Nardi, M. Riedmiller, C. Sammut, and J. Santos-Victor, Eds., vol. 3276, New York: SpringerVerlag: Springer-Verlag, 2005.

[124] -UCHILSIM: A dynamically and visually realistic simulator for the RoboCup four legged league," in Lecture Notes in Computer Science, vol. 3276, D. Nardi, M. Riedmiller, C. Sammut, and J. Santos-Victor, Eds., New York: Springer-Verlag, 2005, pp. 34-45.

[125] J. C. Zagal, J. Ruiz-del Solar, P. Guerrero, and R. Palma, "Evolving visual object recognition for legged robots," in Lecture Notes in Computer Science, vol. 3020, D. Polani, B. Browning, A. Bonarini, and K. Yoshida, Eds., New York: Springer-Verlag, 2004.

[126] J. C. Zagal, J. Ruiz-del Solar, and P. Vallejos, "Back to reality: Crossing the reality gap in evolutionary robotics," presented at the IAV 2004, 5th IFAC Symp. Intell. Auton. Veh., Lisbon, Portugal, 2004. 
Stephan K. Chalup (S'99-A'00-M'04) received the Diploma in mathematics with biology from the University of Heidelberg, Heidelberg, Germany, in 1996 , and the Ph.D. degree from the Queensland University of Technology, Brisbane, Australia, in 2002

He is currently a Senior Lecturer of computer science and software engineering at the University of Newcastle, Callaghan, Australia, where he is also the leader of the Interdisciplinary Machine Learning Research Group and one of the academic chief investigators in the Newcastle Robotics Laboratory. His current research interests include autonomous robots, computational neuroscience, kernel machines, and manifold learning.

Craig L. Murch was born in Chicago, IL. He received the B.Comp.Sc. and B.Math. degrees from the University of Newcastle, Callaghan, Australia, in 2002 and 2003, respectively, where he completed the honors in computer science in 2004.

He is curently a Systems Engineer with the Computer Science Corporation, Macquarie Park, Australia. His current research interests include dimensionality reduction and manifold learning.
Michael J. Quinlan was born in Newcastle, Australia. He received the B.E. degree in software engineering in 2000 and the Ph.D. degree from the University of Newcastle, Callaghan, Australia, in 2006.

His current research interests include quadruped locomotion, support vector machines, and robotic applications of machine learning. 